\title{
Wild Pollinators Enhance Fruit Set of Crops Regardless of Honey Bee Abundance
}

Lucas A. Garibaldi, ${ }^{1 *}$ Ingolf Steffan-Dewenter, ${ }^{2}$ Rachael Winfree, ${ }^{3}$ Marcelo A. Aizen, ${ }^{4}$ Riccardo Bommarco, ${ }^{5}$ Saul A. Cunningham, ${ }^{6}$ Claire Kremen, ${ }^{7}$ Luísa G. Carvalheiro, ${ }^{8,9}$ Lawrence D. Harder, ${ }^{10}$ Ohad Afik, ${ }^{11}$ Ignasi Bartomeus, ${ }^{12}$ Faye Benjamin, ${ }^{3}$ Virginie Boreux, ${ }^{13,14}$ Daniel Cariveau, ${ }^{3}$ Natacha P. Chacoff, ${ }^{15}$ Jan H. Dudenhöffer, ${ }^{16}$ Breno M. Freitas, $^{17}$ Jaboury Ghazoul, ${ }^{14}$ Sarah Greenleaf, ${ }^{7}$ Juliana Hipólito, ${ }^{18}$ Andrea Holzschuh, ${ }^{2}$ Brad Howlett, ${ }^{19}$ Rufus Isaacs, ${ }^{20}$ Steven K. Javorek, ${ }^{21}$ Christina M. Kennedy, ${ }^{22}$ Kristin M. Krewenka, $^{23}$ Smitha Krishnan, ${ }^{14}$ Yael Mandelik, ${ }^{11}$ Margaret M. Mayfield, ${ }^{24}$ Iris Motzke, ${ }^{13,23}$ Theodore Munyuli, ${ }^{25}$ Brian A. Nault, ${ }^{26}$ Mark Otieno, ${ }^{27}$ ]essica Petersen, ${ }^{26}$ Gideon Pisanty, ${ }^{11}$ Simon G. Potts, ${ }^{27}$ Romina Rader, ${ }^{28}$ Taylor H. Ricketts, ${ }^{29}$ Maj Rundlöf, ${ }^{5,30}$ Colleen L. Seymour, ${ }^{31}$ Christof Schüepp, ${ }^{32,33}$ Hajnalka Szentgyörgyi, ${ }^{34}$ Hisatomo Taki, ${ }^{35}$ Teja Tscharntke, $^{23}$ Carlos H. Vergara, ${ }^{36}$ Blandina F. Viana, ${ }^{18}$ Thomas C. Wanger, ${ }^{23}$ Catrin Westphal, $^{23}$ Neal Williams, ${ }^{37}$ Alexandra M. Klein ${ }^{13}$

The diversity and abundance of wild insect pollinators have declined in many agricultural landscapes. Whether such declines reduce crop yields, or are mitigated by managed pollinators such as honey bees, is unclear. We found universally positive associations of fruit set with flower visitation by wild insects in 41 crop systems worldwide. In contrast, fruit set increased significantly with flower visitation by honey bees in only $14 \%$ of the systems surveyed. Overall, wild insects pollinated crops more effectively; an increase in wild insect visitation enhanced fruit set by twice as much as an equivalent increase in honey bee visitation. Visitation by wild insects and honey bees promoted fruit set independently, so pollination by managed honey bees supplemented, rather than substituted for, pollination by wild insects. Our results suggest that new practices for integrated management of both honey bees and diverse wild insect assemblages will enhance global crop yields.

$\mathrm{H}$ uman persistence depends on many natural processes, termed ecosystem services, which are usually not accounted for in market valuations. The global degradation of such services can undermine the ability of agriculture to meet the demands of the growing, increasingly affluent, human population $(1,2)$. Pollination of crop flowers by wild insects is one such vulnerable ecosystem service (3), as the abundance and diversity of these insects are declining in many agricultural landscapes $(4,5)$. Globally, yields of insect-pollinated crops are often managed for greater pollination through the addition of honey bees (Apis mellifera $\mathrm{L}$.) as an agricultural input (Fig. 1) (6-8). Therefore, the potential impact of wild pollinator decline on crop yields is largely unknown. Nor is it known whether increasing application of honey bees ( 9 ) compensates for losses of wild pollinators, or even promotes these losses.

Fruit set, the proportion of a plant's flowers that develop into mature fruits or seeds, is a key component of crop yield (fig. S1). Wild insects may increase fruit set by contributing to polli- nator abundance, species number (richness), equity in relative species abundance (evenness), or some combination of these factors. Increased pollinator abundance, and therefore the rate of visitation to crop flowers, should augment fruit set at a decelerating rate until additional individuals do not further increase fruit set (e.g., pollen saturation) or even decrease fruit set (e.g., pollen excess) (10-12). Richness of pollinator species should increase the mean, and reduce the variance, of fruit set (13) because of complementary pollination among species $(14,15)$, facilitation $(16,17)$, or "sampling effects" $(18)$, among other mechanisms $(19,20)$. Pollinator evenness may enhance fruit set via complementarity, or diminish it if a dominant species (e.g., honey bee) is the most effective pollinator (21). To date, the few studies on the importance of pollinator richness for crop pollination have revealed mixed results (22), the effects of evenness on pollination services remain largely unknown, and the impact of wild insect loss on fruit set has not been evaluated globally for animal-pollinated crops.

We tested four predictions arising from the assumptions that wild insects effectively pollinate a broad range of crops, and that their role can be replaced by increasing the abundance of honey bees in agricultural fields: (i) For most crops, both wild insect and honey bee visitation enhance pollen deposition on stigmas of flowers; (ii) consequently, for most crops, wild insect and honey bee visitation both improve fruit set; (iii) visitation by wild insects promotes fruit set only when honey bees visit infrequently (i.e., there is a negative interaction effect between wild insect visitation and honey bee visitation); and (iv) pollinator assemblages with more species benefit fruit set only when honey bees visit infrequently (i.e., there is a negative interaction effect between richness and honey bee visitation).

To test these predictions, we collected data at 600 fields on all continents, except Antarctica, for 41 crop systems (Fig. 1). Crops included a
${ }^{1}$ Sede Andina, Universidad Nacional de Río Negro (UNRN) and Consejo Nacional de Investigaciones Cientfíicas y Técnicas (CONICET), Mitre 630, CP 8400, San Carlos de Bariloche, Río Negro, Argentina. ${ }^{2}$ Department of Animal Ecology and Tropical Biology, Biocentre, University of Würzburg, Am Hubland D-97074 Würzburg, Germany. ${ }^{3}$ Department of Ecology, Evolution and Natural Resources, Rutgers University, New Brunswick, N] 08901, USA. ${ }^{4}$ Laboratorio Ecotono, Centro Regional Universitario Bariloche (CRUB), Universidad Nacional del Comahue and Instituto de Investigaciones en Biodiversidad y Medioambiente (INIBIOMA), CP 8400, San Carlos de Bariloche, Río Negro, Argentina. ${ }^{5}$ Department of Ecology, Swedish University of Agricultural Sciences, SE-750 07 Uppsala, Sweden. ${ }^{6} \mathrm{CSIRO}$ Ecosystem Sciences, Box 1700, Canberra, AC, Australia. ${ }^{7}$ Environmental Sciences Policy and Management, 130 Mulford Hall, University of California, Berkeley, CA 94720, USA. ${ }^{8}$ School of Biology, University of Leeds, Leeds LS2 9JT, UK. 'Naturalis Biodiversity Center, P.O. Box 9517, 2300RA Leiden, Netherlands. ${ }^{10}$ Department of Biological Sciences, University of Calgary, Calgary, Alberta T2N 1N4, Canada. ${ }^{11}$ Department of Entomology, Robert H. Smith Faculty of Agriculture, Food and Environment, Hebrew University of Jerusalem, Rehovot, Israel. ${ }^{12}$ Department of Entomology, Evolution and Natural Resources, Rutgers University, New Brunswick, N] 08901, USA. ${ }^{13}$ Institute of Ecology, Ecosystem Functions, Leuphana University, 21335 Lüneburg, Germany. ${ }^{14}$ Department of Environmental Systems Science, ETH Zürich, 8092 Zürich, Switzerland. ${ }^{15}$ Instituto de Ecología Regional, Facultad de Ciencias Naturales e IML, Universidad Nacional de Tucumán, CC 34, CP 4017, Yerba Buena, Tucumán, Argentina. ${ }^{16}$ Ecological Farming Systems, Agroscope Reckenholz-Tänikon Research Station ART, Zürich, Switzerland. ${ }^{17}$ Universidade Federal do Ceará, Departamento de Zootecnia-CCA, Campus Universitário do Pici, Bloco 808. 60.356-000 Fortaleza-CE, Brazil. ${ }^{18}$ Universidade Federal da Bahia, Departamento de Zoologia, Instituto de Biologia, Rua Barão de Geremoabo, s/n. 40.170-110 Salvador-BA, Brazil. ${ }^{19}$ New Zealand Institute for Plant and Food Research, Private Bag 4704, Christchurch, New Zealand. ${ }^{20}$ Department of Entomology, Michigan State University, East Lansing, MI 48824, USA. ${ }^{21}$ Agriculture and Agri-Food Canada, Atlantic Food and Horticulture Research Centre, Kentville, Nova Scotia, Canada. ${ }^{22}$ Development by Design Program, Nature Conservancy, Fort Collins, CO 80524, USA. ${ }^{23}$ Agroecology, Department of Crop Sciences, Georg-August-University, Grisebachstr. 6, 37077 Goettingen, Germany. ${ }^{24}$ School of Biological Sciences and Ecology Centre, University of Queensland, Brisbane, QLD, Australia. ${ }^{25}$ Department of Biology, National Center for Research in Natural Sciences, CRSN-Lwiro, D.S. Bukavu, Sud-Kivu, Demo- cratic Republic of Congo. ${ }^{26}$ Department of Entomology, Cornell University, New York State Agricultural Experiment Station, 630 West North Street, Geneva, NY 14456, USA. ${ }^{27}$ School of Agriculture, Policy and Development, University of Reading, Reading RG6 6AR, UK. ${ }^{28}$ Department of Physical Geography and Quaternary Geology, Stockholm University, SE 10691 Stockholm, Sweden. ${ }^{29}$ Gund Institute for Ecological Economics, University of Vermont, Burlington, VT 05401, USA. ${ }^{30}$ Department of Biology, Lund University, SE-223 62 Lund, Sweden. ${ }^{31}$ Applied Biodiversity Research Division, South African National Institute of Biodiversity, Private Bag X7, Claremont, 7735, South Africa. ${ }^{32}$ Institute of Ecology and Evolution, Community Ecology, University of Bern, 3012 Bern, Switzerland. ${ }^{33}$ Ecosystem Analysis, University of Koblenz-Landau, Fortstrasse 7, D-76829 Landau, Germany. ${ }^{34}$ Institute of Environmental Sciences, Jagiellonian University, ul. Gronostajowa 7, Kraków 30-387, Poland. ${ }^{35}$ Department of Forest Entomology, Forestry and Forest Products Research Institute, 1 Matsunosato, Tsukuba, Ibaraki 305-8687, Japan. ${ }^{36}$ Departamento de Ciencias Químico-Biológicas, Universidad de las Américas Puebla, Cholula, Puebla, Mexico. ${ }^{37}$ Department of Entomology, University of California, Davis, CA 96616, USA.

*Corresponding author. E-mail: Igaribaldi@unrn.edu.ar 
wide array of animal-pollinated, annual and perennial fruit, seed, nut, and stimulant crops; predominantly wind-pollinated crops were not considered (fig. S2 and table S1). The sampled fields were subject to a diversity of agricultural practices, including extensive monocultures and small or diversified systems (fig. S2 and table $\mathrm{S} 1$ ), fields stocked with low to high density of honey bees (Fig. 1 and table S2), and fields with low to high abundance and diversity of wild insects (fig. S3 and table S2). For each field, we measured flower visitation per unit of time (hereafter "visitation") for each insect species, from which we estimated species richness and evenness (23). We quantified pollen deposition for 14 systems as the number of pollen grains per stigma, and fruit set (fig. S1) for 32 systems as the percentage of flowers setting mature fruits or seeds. Spatial or temporal variation of pollen deposition and fruit set were measured as the coefficient of variation $(\mathrm{CV})$ over sample points or days within each field (10). The multilevel data provided by fields within systems were analyzed with general linear mixed-effects models that included crop system as a random effect, and wild insect visitation, honey bee visitation, evenness, richness, and all their interactions as fixed effects. Best-fitting models were selected on the basis of the Akaike information criterion (AIC) (23).

In agreement with the first prediction, crops in fields with more flower visits received more pollen on stigmas, with an overall $74 \%$ stronger influence of visitation by honey bees than by wild insects (Fig. 2A and table S3). Honey bee visitation significantly increased pollen deposition (i.e., confidence intervals for individual regression coefficients, $\beta_{\mathrm{i}}$, did not include zero) in 7 of 10 crop systems, and wild insects in 10 of 13 systems (fig. S4). Correspondingly, increased wild insect and honey bee visitation reduced variation in pollen deposition among samples (fig. S5).

Contrary to the second prediction, fruit set increased significantly with wild insect visitation in all crop systems, but with honey bee visitation in only $14 \%$ of the systems (Fig. $2 \mathrm{~B}$ ). In addition, fruit set increased twice as strongly with visitation by wild insects as with visitation by honey bees (Fig. 2A). These partial regression coefficients did not differ simply because of unequal abundance, nor because of disparate variation in visitation between wild insects and honey bees. In crop systems visited by both honey bees and wild insects, honey bees accounted for half of the visits to crop flowers $[$ mean $=51 \%$; 95\% confidence interval $(\mathrm{CI})=40$ to $62 \%$ ], and among-field $\mathrm{CVs}$ for visitation by honey bees $($ mean $=73 \%$; $95 \% \mathrm{CI}=57$ to $88 \%$ ) and by wild insects (mean $=79 \% ; 95 \% \mathrm{CI}=62$ to $96 \%$ ) were equivalent. Furthermore, wild insect visitation had stronger effects than honey bee visitation, regardless of whether honey bees were managed or feral (fig. S6) and, comparing across systems, even where only wild insects or honey bees occurred (Fig. 2B). Wild insect visitation alone predicted fruit set better than did honey bee visitation alone $\left(\Delta_{\mathrm{AIC}}=16\right.$; table $\mathrm{S} 4$, model $\mathrm{F}$ versus model $\mathrm{M})$. Correspondingly, the $\mathrm{CV}$ of fruit set decreased with wild insect visitation but varied independently of honey bee visitation (fig. S5).

Pollinator visitation affected fruit set less strongly than did pollen deposition on stigmas (compare regression coefficients in Fig. 2A). This contrast likely arose from pollen excess, filtering of pollen tubes by post pollination processes, and/or seed abortion $(11,24)$, and so reflects pol- lination quality, in part. Intriguingly, the difference in coefficients between pollen deposition and fruit set for honey bees greatly exceeded that for wild insects (Fig. 2A); this finding indicates that wild insects provide better-quality pollination, such as greater cross-pollination $(14,16,17,19)$. These results occurred regardless of which crop systems were selected (fig. S7), sample size (fig. S8), the relative frequency of honey bees in the pollinator assemblage (dominance) among systems, the pollinator dependence of crops, or whether the crop species were herbaceous or woody, or native or exotic (fig. S9). Poor-quality pollination could arise if foraging behavior on focal resources typical of honey bees $(16,17)$ causes pollen transfer between flowers of the same plant individual or the same cultivar within a field, thereby limiting crosspollination and increasing the incidence of selfpollen interference and inbreeding depression (24). The smaller difference in coefficients between pollen deposition and fruit set for wild insects, and the stronger effect of wild insect visitation on fruit set, suggest that management to promote diverse wild insects has great potential to improve the global yield of animal-pollinated crops.

The third prediction was also not supported. Fruit set consistently increased with visitation by wild insects, even where honey bees visited frequently (i.e., no statistical interaction; Fig. 2, A and C). In particular, the best-fitting model (lowest AIC) for fruit set included additive effects of visitation by both wild insects and honey bees (table S4, model P), which suggests that managed honey bees supplement the pollination service of wild insects but cannot replace it. Overall, visitations by wild insects and honey bees were not correlated among fields (fig. S10), providing no evidence either for

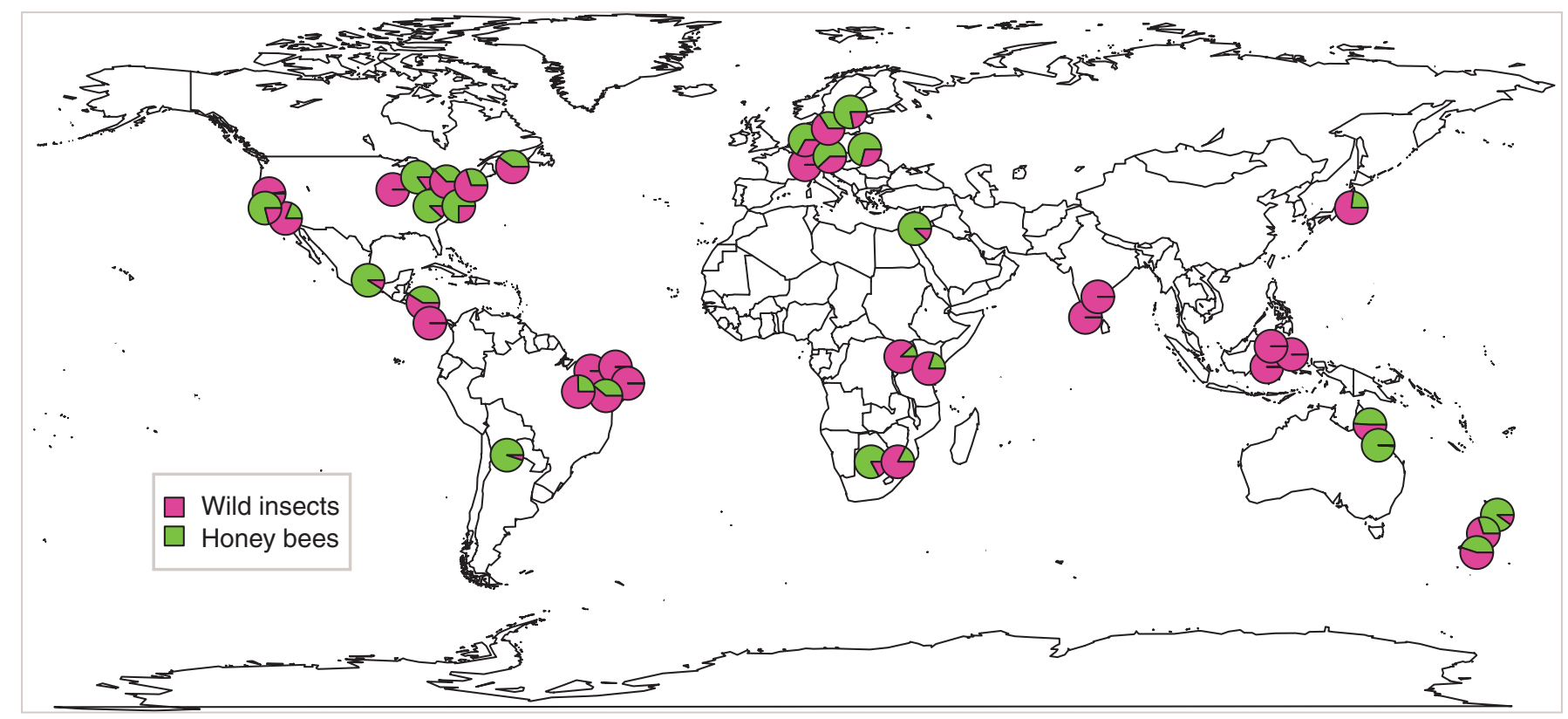

Fig. 1. Relative visitation by honey bees and wild insects to flowers of 41 crop systems on six continents. Honey bees occur as domesticated colonies in transportable hives worldwide, as a native species in Europe (rarely) and Africa, or as feral populations in all other continents except Antarctica. 
competition for the resources obtained from crop flowers (pollen, nectar) or for density compensation (13) between wild insects and honey bees at the field scale. Even if honey bees displace wild insects (or vice versa) at the flower scale $(16,17)$, this is unlikely to scale up to the field, as indicated by our data, if mass-flowering crops provide floral resources in excess of what can be exploited by local pollinator populations. Therefore, insect pollinators appear not to be limited by crop floral resources, but crop yield was commonly pollen-limited, as crops set more fruit in fields with more visitation by pollinators (Fig. 2).

Contrary to the fourth prediction, fruit set increased with flower-visitor richness indepen- dently of honey bee visitation (fig. S11). Correspondingly, the CVs of fruit set decreased with richness; in contrast, evenness did not affect the mean or CV of fruit set (figs. S12 and S13). Visitation by wild insects increased strongly with richness (Fig. 3) and improved model fit (lower AIC), even when richness was included in the model (table S4, model B versus model G). However, richness did not enhance model fit when added to a model with wild insect visitation (table S4, model F versus model G), which suggests that the effects of richness on fruit set reflect increased wild insect visitation (i.e., colinear effects; fig. S13). Like wild insect visitation (fig. S10), richness did not correlate with honey bee visitation (table S5). Previous studies have shown that agricultural intensification reduces both species richness of pollinator assemblages and wild insect visitation $(4,5,13,19)$. Our results for multiple crop systems further demonstrate that fields with fewer pollinator species experience less visitation by wild insects and reduced fruit set, independent of species evenness or honey bee visitation. Globally, wild insect visitation is an indicator of both species richness and pollination services, and its measurement can be standardized easily and inexpensively among observers in field samples (25).

Large, active colonies of honey bees provide abundant pollinators that can be moved as needed, hence their appeal for pollination management in most animal-pollinated crops $(6-8,26)$. By
A

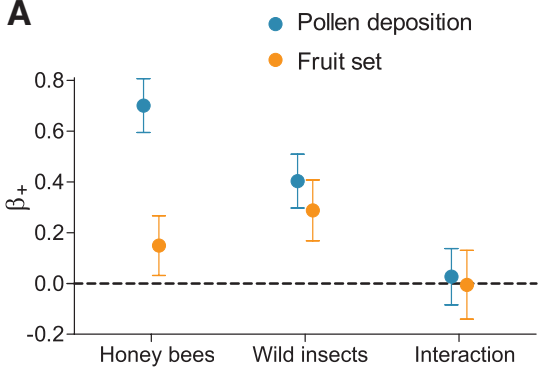

B

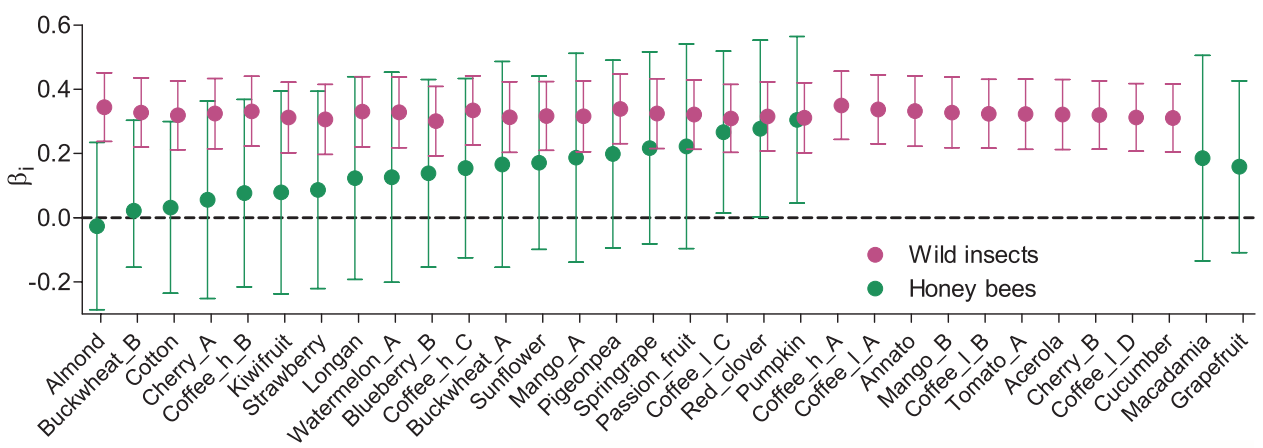

Fig. 2. Wild insect visitation to crop flowers enhances reproduction in all crops examined (regression coefficient $\beta_{i}>0$ ), whereas honey bee visitation has weaker effects overall. (A) Overall partial regression coefficients $\left(\beta_{+} \pm 95 \% \mathrm{Cl}\right)$ for the direct and interacting effects of visitation by wild insects and honey bees on pollen deposition or fruit set (models $\mathrm{R}$ and $\mathrm{Q}$ in tables S3 and S4, respectively). (B) Slopes $\left(\beta_{i} \pm 95 \% \mathrm{Cl}\right.$ ) represent the effects of visitation by wild insects or honey bees on fruit set for individual crop systems. Cases at the right are systems in which only wild insects or only honey bees were present. Data from individual crop systems were standardized by $z$ scores prior to analysis, permitting comparison of regression coefficients in all panels. Letters after crop names indicate different regions (table S1); for example, Mango_A and Mango_B are located in South Africa and Brazil, respectively. (C) Given the absence of interaction between the effects of visitation by wild insects and honey bees, maximum fruit set is achieved with high visitation by both wild insects and honey bees (upper right area of graph). The plane in orange is the overall regression (model $\mathrm{P}$ in table S4; the inclination of the surface in the $y$ and $x$ directions reflects the $\beta_{+}$for visitation of wild insects and honey bees, respectively), and each point is a field in a crop system (fruit set increases from cyan to dark blue).

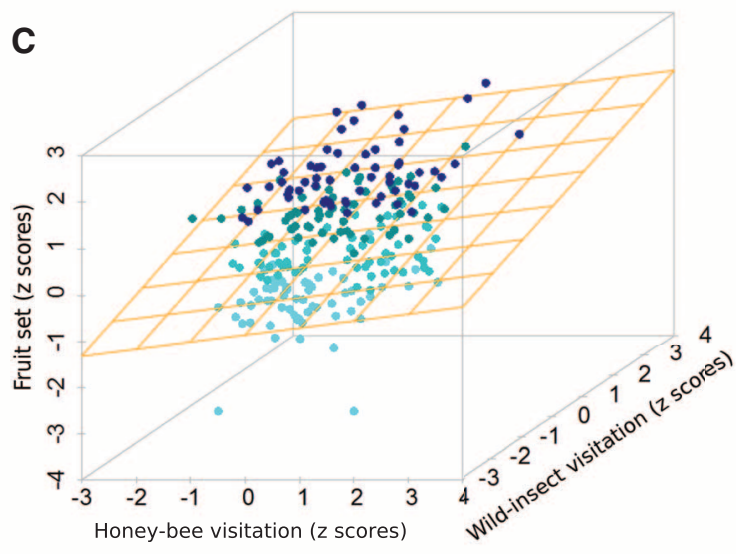

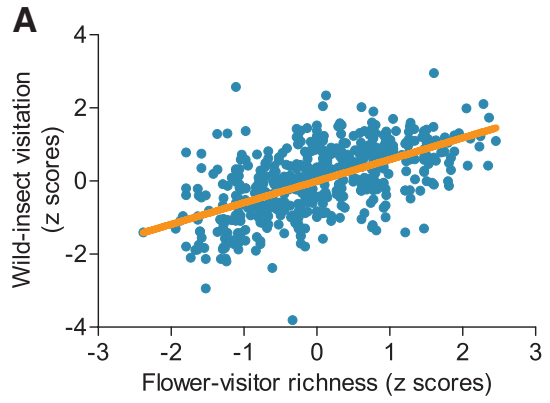

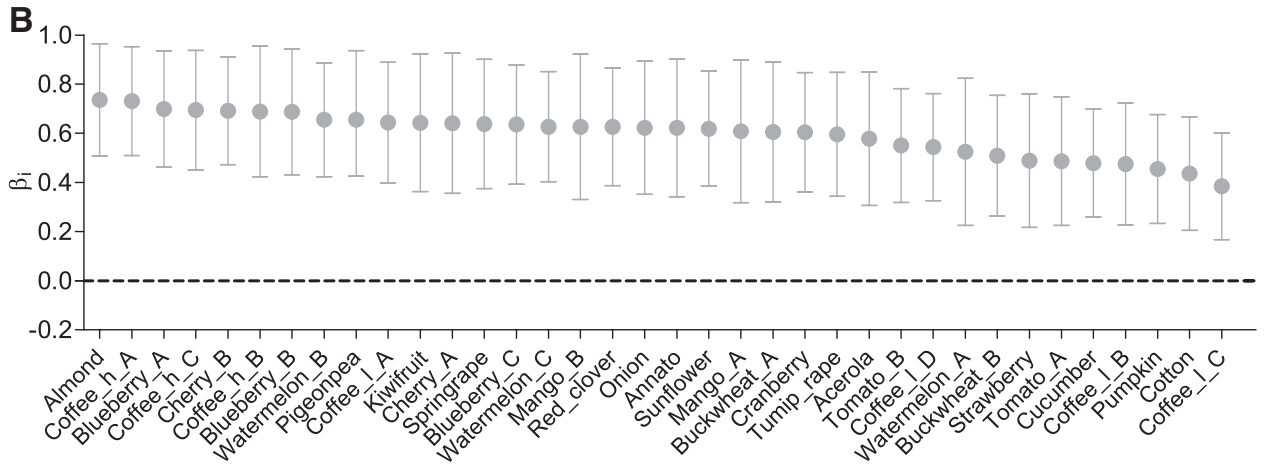

Fig. 3. Globally, rate of visitation to crop flowers by wild insects increases with flower-visitor richness. (A) The line is the overall regression, and each point is a field in a crop system. (B) Slopes $\left(\beta_{\mathrm{i}} \pm 95 \% \mathrm{Cl}\right)$ represent the effect of richness on wild insect visitation for individual crop systems. Data from individual crop systems were standardized by $z$ scores prior to analysis (after log-transformation for visitation), permitting direct comparison of regression coefficients. 
comparison, methods for maintaining diverse wild insects for crop pollination are less developed, and research on such pollination services is more recent $(3,16,17,20,26,27)$ (table $\mathrm{S} 1)$. Although honey bees are generally viewed as a substitute for wild pollinators $(3,6-8)$, our results show that they neither maximize pollination nor fully replace the contributions of diverse wild insect assemblages to fruit set for a broad range of crops and agricultural practices on all continents with farmland. These conclusions hold even for crops stocked routinely with high densities of honey bees for pollination, such as almond, blueberry, and watermelon (Fig. 2 and table S2). Dependence on a single species for crop pollination also carries the risks associated with predator, parasite, and pathogen development $(4,20,28)$.

Our results support integrated management policies (29) that include pollination by wild insects as ecosystem service providers, along with managed species - such as honey bees, bumble bees (Bombus spp.), leafcutter bees (Megachile spp.), mason bees (Osmia spp.), and stingless bees (Meliponini) - as agricultural inputs, where they are not invasive species. Such policies should include conservation or restoration of natural or seminatural areas within croplands, promotion of land-use heterogeneity (patchiness), addition of diverse floral and nesting resources, and consideration of pollinator safety as it relates to pesticide application $(3,16,17,20,27)$. Some of these recommendations entail financial and op- portunity costs, but the benefits of implementing them include mitigation against soil erosion as well as improvements in pest control, nutrient cycling, and water-use efficiency (30). Without such changes, the ongoing loss of wild insects $(4,5)$ is destined to compromise agricultural yields worldwide.

\section{References and Notes}

1. L. Roberts, Science 333, 540 (2011).

2. D. Tilman et al., Science 292, 281 (2001).

3. A.-M. Klein et al., Proc. R. Soc. London Ser. B 274, 303 (2007).

4. S. G. Potts et al., Trends Ecol. Evol. 25, 345 (2010).

5. L. A. Garibaldi et al., Ecol. Lett. 14, 1062 (2011).

6. R. A. Morse, Trends Ecol. Evol. 6, 337 (1991).

7. R. M. Goodwin, H. M. Cox, M. A. Taylor, L. J. Evans, H. M. McBrydie, New Zeal. J. Crop Hort. 39, 7 (2011)

8. R. R. Rucker, W. N. Thurman, M. Burgett, Am. J. Agric. Econ. 94, 956 (2012).

9. M. A. Aizen, L. D. Harder, Curr Biol 19, 915 (2009).

10. L. A. Garibaldi, M. A. Aizen, A.-M. Klein, S. A. Cunningham, L. D. Harder, Proc. Natl. Acad. Sci. U.S.A. 108, 5909 (2011).

11. N. P. Chacoff, M. A. Aizen, V. Aschero, Proc. R. Soc. London Ser. B 275, 907 (2008).

12. W. F. Morris, D. P. Vázquez, N. P. Chacoff, Ecology 91 1276 (2010).

13. R. Winfree, C. Kremen, Proc. R. Soc. London Ser. B 276, 229 (2009).

14. P. Hoehn, T. Tscharntke, J. M. Tylianakis, I. Steffan-Dewenter, Proc. R. Soc. London Ser. B 275, 2283 (2008).

15. N. Blüthgen, A.-M. Klein, Basic Appl. Ecol. 12, 282 (2011).

16. L. G. Carvalheiro et al., Ecol. Lett. 14, 251 (2011).

17. S. S. Greenleaf, C. Kremen, Proc. Natl. Acad. Sci. U.S.A. 103, 13890 (2006)

18. B. J. Cardinale et al., Nature 443, 989 (2006).

19. A.-M. Klein, C. Müller, P. Hoehn, C. Kremen, in Biodiversity, Ecosystem Functioning, and Human
Wellbeing: An Ecological and Economic Perspective,

D. E. Bunker, A. Hector, M. Loreau, C. Perrings,

S. Naeem, Eds. (Oxford Univ. Press, Oxford, 2009), pp. 195-208.

20. T. Tscharntke, A.-M. Klein, A. Kruess, I. Steffan-Dewenter, C. Thies, Ecol. Lett. 8, 857 (2005).

21. H. Hillebrand, D. M. Bennett, M. W. Cadotte, Ecology 89, 1510 (2008)

22. B. J. Cardinale et al., Nature 486, 59 (2012).

23. See supplementary materials on Science Online.

24. M. A. Aizen, L. D. Harder, Ecology 88, 271 (2007).

25. C. Kremen, K. S. Ullman, R. W. Thorp, Conserv. Biol. 25, 607 (2011)

26. K. S. Delaplane, D. F. Mayer, Crop Pollination by Bees (CABI, New York, 2000).

27. C. Kremen et al., Ecol. Lett. 10, 299 (2007).

28. R. Winfree, N. M. Williams, ]. Dushoff, C. Kremen, Ecol. Lett. 10, 1105 (2007).

29. A. Aebi et al., Trends Ecol. Evol. 27, 142 (2012).

30. S. D. Wratten, M. Gillespie, A. Decourtye, E. Mader, N. Desneux, Agric. Ecosyst. Environ. 159, 112 (2012).

Acknowledgments: Funding acknowledgments and author contributions are listed in the supplementary materials. The data used in the primary analyses are available in the supplementary materials, including tables $\mathrm{S} 1$ and $\mathbf{S 2}$.

\section{Supplementary Materials}

www.sciencemag.org/cgi/content/full/science.1230200/DC1 Materials and Methods

Supplementary Tex

Figs. S1 to S13

Tables S1 to S5

References (31-79)

Database S1

14 September 2012; accepted 5 February 2013

Published online 28 February 2013;

$10.1126 /$ science. 1230200

\section{Plant-Pollinator Interactions}

\section{over 120 Years: Loss of Species, Co-Occurrence, and Function}

\author{
Laura A. Burkle, ${ }^{1,2 \star}$ John C. Marlin, ${ }^{3}$ Tiffany M. Knight ${ }^{1}$
}

Using historic data sets, we quantified the degree to which global change over 120 years disrupted plant-pollinator interactions in a temperate forest understory community in Illinois, USA. We found degradation of interaction network structure and function and extirpation of $50 \%$ of bee species. Network changes can be attributed to shifts in forb and bee phenologies resulting in temporal mismatches, nonrandom species extinctions, and loss of spatial co-occurrences between extant species in modified landscapes. Quantity and quality of pollination services have declined through time. The historic network showed flexibility in response to disturbance; however, our data suggest that networks will be less resilient to future changes.

A lmost $90 \%$ of flowering plant species, including many important crop species (1), rely on animal pollinators (2). Plantpollinator interaction networks may be particularly susceptible to anthropogenic changes, owing to their sensitivity to the phenology, behavior,

${ }^{1}$ Washington University, Department of Biology, St. Louis, MO 63130, USA. ${ }^{2}$ Montana State University, Department of Ecology, Bozeman, MT 59717, USA. ${ }^{3}$ University of Illinois, Illinois Sustainable Technology Center, Champaign, IL 61820, USA. *Corresponding author. E-mail: laura.burkle@montana.edu physiology, and relative abundances of multiple species (3). Alternatively, the overall structure of plant-pollinator networks might be robust to perturbations because of a high degree of nestedness and redundancy in interactions (4).

Several authors have speculated about how changes in biodiversity (5) and phenology $(6-8)$ might translate into changes in the structure $(9,10)$ and stability (11) of complex interaction networks. However, there has been a lack of historical data on plant-pollinator networks and phenologies for both plants and insects in the same community.
By using an extensive and unique data set, we were able to examine changes in plant-pollinator network structure and phenologies of forbs and bees across more than a century of anthropogenic change.

In the late 1800 s, Charles Robertson meticulously collected and categorized insect visitors to plants, as well as plant and insect phenologies, in natural habitats near Carlinville, Illinois, USA (12-14). Over the next century, this region experienced severe habitat alteration, including conversion of most forests and prairies to agriculture, and moderate climatic warming of $2^{\circ} \mathrm{C}$ in winter and spring. In 2009 and 2010, we revisited the area studied by Robertson and re-collected data on the phenologies and structure of a subset of this network - 26 spring-blooming forest understory forbs and their 109 pollinating bees (15). Hence, we could quantify changes in network structure, local bee diversity, and phenologies of forbs and bees. Further analyses and a null model determined the degree to which changes in network structure and bee diversity were attributed to species' traits, phenological mismatches, and land-use factors that spatially separate interacting species. To examine shifts in the quantity of pollinator services, we used a second historical data set from Carlinville collected in the early 1970s (16), examining the diversity and visitation rate of bees to the most important floral resource in this network (Claytonia virginica). 


\section{ERRATUM}

Erratum for the Report: "Wild Pollinators Enhance Fruit Set of Crops Regardless of Honey Bee Abundance" by L. A. Garibaldi, I. Steffan-Dewenter, R. Winfree, M. A. Aizen, R. Bommarco, S. A. Cunningham, C. Kremen, L. G. Carvalheiro, L. D. Harder, O. Afik, I. Bartomeus, F. Benjamin, V. Boreux, D. Cariveau, N. P. Chacoff, J. H. Dudenhöffer, B. M. Freitas, J. Ghazoul, S. Greenleaf, J. Hipólito, A. Holzschuh, B. Howlett, R. Isaacs, S. K. Javorek, C. M. Kennedy, K. M. Krewenka, S. Krishnan, Y. Mandelik, M. M. Mayfield, I. Motzke, T. Munyuli, B. A. Nault, M. Otieno, J. Petersen, G. Pisanty, S. G. Potts, R. Rader, T. H. Ricketts, M. Rundlöf, C. L. Seymour, C. Schüepp, H. Szentgyörgyi, H. Taki, T. Tscharntke, C. H. Vergara, B. F. Viana, T. C. Wanger, C. Westphal, N. Williams, A. M. Klein

In the Report "Wild Pollinators Enhance Fruit Set of Crops Regardless of Honey Bee Abundance," it is possible that some pollinator species were misidentified in lowland coffee, Ugan$\mathrm{da}$, one of the 41 studies included in the synthesis. This potential misidentification does not invalidate the analyses, conclusions, or the wider implications of the study. The results are not sensitive to which of the 41 studies are included, because the authors performed several analyses with different subsets of studies, and they all showed similar results. Furthermore, the mixed-effect models allow for individual variation in trends for each study. The results of these analyses depend on the consistency of patterns across all of the 41 studies sampled in 600 fields and are not influenced to any large extent by a particular pattern occurring in just one study. The main analysis compared the flower visitation rate of honey bees versus all wild insect species combined. This analysis should be largely insensitive to identification concerns because honey bees were readily separable from other species in all studies. Indeed, the analyses performed in the synthesis do not make use of the species names of the wild insects (see database S1). 


\section{Science}

\section{Wild Pollinators Enhance Fruit Set of Crops Regardless of Honey Bee Abundance}

Lucas A. Garibaldi, Ingolf Steffan-Dewenter, Rachael Winfree, Marcelo A. Aizen, Riccardo Bommarco, Saul A. Cunningham, Claire Kremen, Luísa G. Carvalheiro, Lawrence D. Harder, Ohad Afik, Ignasi Bartomeus, Faye Benjamin, Virginie Boreux, Daniel Cariveau, Natacha P. Chacoff, Jan H. Dudenhöffer, Breno M. Freitas, Jaboury Ghazoul, Sarah Greenleaf, Juliana Hipólito, Andrea Holzschuh, Brad Howlett, Rufus Isaacs, Steven K. Javorek, Christina M. Kennedy, Kristin M. Krewenka, Smitha Krishnan, Yael Mandelik, Margaret M. Mayfield, Iris Motzke, Theodore Munyuli, Brian A. Nault, Mark Otieno, Jessica Petersen, Gideon Pisanty, Simon G. Potts, Romina Rader, Taylor H. Ricketts, Maj Rundlöf, Colleen L. Seymour, Christof Schüepp, Hajnalka Szentgyörgyi, Hisatomo Taki, Teja Tscharntke, Carlos H. Vergara, Blandina F. Viana, Thomas C. Wanger, Catrin Westphal, Neal Williams and Alexandra M. Klein

Science 339 (6127), 1608-1611.

DOI: 10.1126/science.1230200originally published online February 28, 2013

\section{Honeybees Can't Do It Alone}

The majority of food crops require pollination to set fruit with the honeybee providing a pollination workhorse, with both feral and managed populations an integral component of crop management (see the Perspective by Tylianakis, published online 28 February). Garibaldi et al. (p. 1608, published online 28 February) now show that wild pollinators are also a vital part of our crop systems. In more than 40 important crops grown worldwide, wild pollinators improved pollination efficiency, increasing fruit set by twice that facilitated by honeybees. Burkle et al. (p. 1611, published online 28 February) took advantage of one of the most thorough and oldest data sets available on plant-pollinator interaction networks and recollected data on plant-pollinator interactions after more than 120 years of climate change and landscape alteration. The historical data set consists of observations collected by Charles Robertson near Carlinville, Illinois (USA), in the late 1800s on the phenology of plants and their pollinating insects, as well as information about which plants and pollinators interacted with one another. Many sites were revisited in the early 1970s and in 2009 and 2010 to collect similar plant-pollinator data. Pollinator function has declined through time, with bees showing lower visitation rates and lower fidelity to individual plant species.

ARTICLE TOOLS

SUPPLEMENTARY

MATERIALS

RELATED
CONTENT

REFERENCES http://science.sciencemag.org/content/339/6127/1608

http://science.sciencemag.org/content/suppl/2013/02/28/science.1230200.DC2 http://science.sciencemag.org/content/suppl/2013/02/28/science.1230200.DC1

http://science.sciencemag.org/content/sci/339/6127/1532.full http://science.sciencemag.org/content/sci/339/6127/1611.full http://science.sciencemag.org/content/sci/340/6135/923.2.full http://science.sciencemag.org/content/sci/344/6183/1255213.full

This article cites 67 articles, 6 of which you can access for free http://science.sciencemag.org/content/339/6127/1608\#BIBL

Use of this article is subject to the Terms of Service

Science (print ISSN 0036-8075; online ISSN 1095-9203) is published by the American Association for the Advancement of Science, 1200 New York Avenue NW, Washington, DC 20005. 2017 (C) The Authors, some rights reserved; exclusive licensee American Association for the Advancement of Science. No claim to original U.S. Government Works. The title Science is a registered trademark of AAAS. 
Use of this article is subject to the Terms of Service

Science (print ISSN 0036-8075; online ISSN 1095-9203) is published by the American Association for the Advancement of Science, 1200 New York Avenue NW, Washington, DC 20005. 2017 () The Authors, some rights reserved; exclusive licensee American Association for the Advancement of Science. No claim to original U.S. Government Works. The title Science is a registered trademark of AAAS. 